\title{
PEMBERDAYAAN MASYARAKAT DESA MOJOPURNO MELALUI PELATIHAN PEMBUATAN SABUN DARI LIMBAH MINYAK JELANTAH
}

\author{
Sigit Ari Prabowo ${ }^{1)}$, Muh.Waskito Ardhi' ${ }^{2)}$, Mislan Sasono ${ }^{3)}$ \\ ${ }^{1)}$ FIP, IKIP PGRI Madiun \\ email: sigit27ap@gmail.com \\ ${ }^{2)}$ FPMIPA, IKIP PGRI Madiun \\ email: itokerna@yahoo.co.id \\ ${ }^{3)}$ FPMIPA, IKIP PGRI Madiun \\ email : mislan_fis03@yahoo.com
}

\begin{abstract}
Jelantah oil is used cooking oil waste, this is organic but if mishandled will pollute the environment. Cooking oil is used for frying foods optimum for 4 times the pan. Cooking oil after use more than 4 times the Pan contains a very high cholesterol levels so that harm to human health that consume them. The purpose this implementation to provide training on the utilization of jelantah from Pan crackers at factory crackers Mojopurno for make an organic soap alternatives. Outreach activities are divided into three phases : 1) observation phase, carried out to determine the potential spread of the villagers and the mojopurno primarily citizens around factories manufacturing crackers; 2) stage of training, was implemented to provide skills training through the creation of soap from the raw material of oil jelantah; 3) Stage evaluation, conducted an evaluation the activities of the citizens who have obtained training in the utilization of waste oil jelantah for making soap.
\end{abstract}

Keywords: Jelantah, Soap, Mojopurno

\section{PENDAHULUAN}

Desa Mojopurno secara teritorial masuk ke dalam wilayah Kabupaten Madiun yang berbatasan langsung dengan wilayah Kotamadya Madiun. Mata pencaharian warga desa Mojopurno sangat beraneka ragam. Di desa Mojopurno terdapat beberapa industri pembuatan kerupuk skala industri rumah tangga yang mempunyai kapasitas produksi tinggi.

Pembuatan kerupuk pada pabrik di desa Mojopurno menggunakan bahan minyak goreng untuk menggoreng kerupuk agar siap dipasarkan secara matang. Pemanfaatan minyak goreng dalam proses penggorengan kerupuk tentu tidak dapat dipakai secara terus menerus untuk menggoreng pada frekuensi yang melebihi batas yang menjadi aturan pemakaian minyak goreng.

Minyak goreng berbahan dasar kelapa secara optimum bisa digunakan untuk menggoreng makanan maksimal selama 4 kali penggorengan. Minyak goreng setelah digunakan untuk menggoreng di atas 4 kali penggorengan atau sering disebut minyak jelantah mengandung kadar kolesterol yang sangat tinggi sehingga membahayakan untuk kesehatan manusia yang mengkonsumsinya (Depkes RI Tahun 2007).

Pertumbuhan jumlah penduduk, serta perkembangan industri, restoran, dan usaha fastfood akan menyebabkan dihasilkannya minyak goreng bekas dalam jumlah yang cukup banyak. Minyak goreng bekas ini apabila dikonsumsi dapat menimbulkan penyakit yang membuat tubuh kita kurang sehat dan stamina menurun. Namun apabila minyak goreng bekas tersebut dibuang sangatlah tidak efisien dan mencemari lingkungan. Karena itu minyak goreng bekas dapat dimanfaatkan kembali, salah satunya menjadi produk berbasis minyak seperti sabun.

Sabun merupakan senyawa natrium atau kalium dengan asam lemak dari minyak nabati atau lemak hewani berbentuk padat, lunak atau cair, dan berbusa. Sabun dihasilkan oleh proses saponifikasi, yaitu hidrolisis lemak menjadi asam lemak dan gliserol dalam kondisi basa. Pembuat kondisi basa yang biasa digunakan adalah Natrium Hidroksida $(\mathrm{NaOH})$ dan Kalium Hidroksida (KOH). Jika basa yang digunakan adalah $\mathrm{NaOH}$, maka produk reaksi berupa sabun keras (padat), sedangkan basa yang digunakan berupa $\mathrm{KOH}$ maka produk reaksi berupa sabun cair (Ketaren, 2006).

Menurut penelitian Nur Aisiyah (2009), menjelaskan bahwa minyak jelantah mempunyai potensi untuk bahan dasar sabun dengan perlakuan khusus secara kimiawi yaitu reaksi saponifikasi. Hal tersebut tentunya berkontribusi untuk mengurangi pembuangan limbah minyak jelantah ke lingkungan, baik itu 
yang berasal dari pabrik ataupun dari dapur rumah tangga.

Berdasarkan analisa uraian di atas, maka penulis tertarik untuk memberikan pelatihan pemanfaatan limbah minyak jelantah bekas penggorengan kerupuk di pabrik kerupuk desa Mojopurno untuk pembuatan sabun organik alternatif.

\section{METODE PELAKSANAAN PROGRAM}

Metode kegiatan yang digunakan adalah melalui pelatihan pembuatan sabun dari limbah minyak jelantah pada kelompok masyarakat desa mojopurno yang diselenggarakan selama tiga kali pertemuan.

Kegiatan pengabdian dibagi menjadi 3 tahapan, yaitu tahap observasi, tahap pelatihan, dan tahap monitoring evaluasi kegiatan.

Kegiatan tahap observasi dilaksanakan untuk mengetahui potensi dan sebaran masyarakat desa mojopurno, terutama pada warga di sekitar pabrik pembuatan kerupuk dan pihak pengusaha serta karyawannya. Selanjutnya hasil observasi dugunakan sebagai dasar acuan untuk melaksanakan tahapan kegiatan pelatihan berikutnya

Kegiatan tahap pelatihan dilaksanakan untuk memberikan bekal ketrampilan melalui pelatihan pembuatan sabun dari bahan dasar minyak jelantah.

Pada tahapan monitoring tim kami melakukan pemantauan kegiatan yang sudah dilakukan oleh kelompok masyarakat yang telah memperoleh pelatihan pemanfaatan limbah minyak jelantah untuk bahan dasar pembuatan sabun.

\section{HASIL DAN PEMBAHASAN}

Masyarakat yang berpartisipasi adalah seluruh warga Desa Mojopurno yang hadir di Balai Desa Mojopurno pada tanggal 4-5 Juli 2014.

Pada tahapan awal, masyarakat yang hadir mengikuti pelatihan di Balai Desa dijelaskan mengenai potensi pemanfaatan limbah khususnya minyak jelantah. warga diberikan penjelasan tahapan - tahapan pembuatan sabun dari minyak jelantah, dengan prosedur sebagai berikut :

- Menyiapkan air $110 \mathrm{ml}$ di mangkok

- Menambahkan 35 gr NaOH

- Diaduk sampai larut, kemudian didiamkan 20 menit

- Memasukkan minyak jelantah yang telah disaring ke dalam campuran

- Mengaduk secara perlahan hingga tercampur
- Memasukkan parfum ke dalam campuran, sambil diaduk hingga kental

- Menambahkan pewarna bila perlu

- Memasukkan campuran ke dalam cetakan

- Diamkan hingga memadat

- Sabun siap digunakan

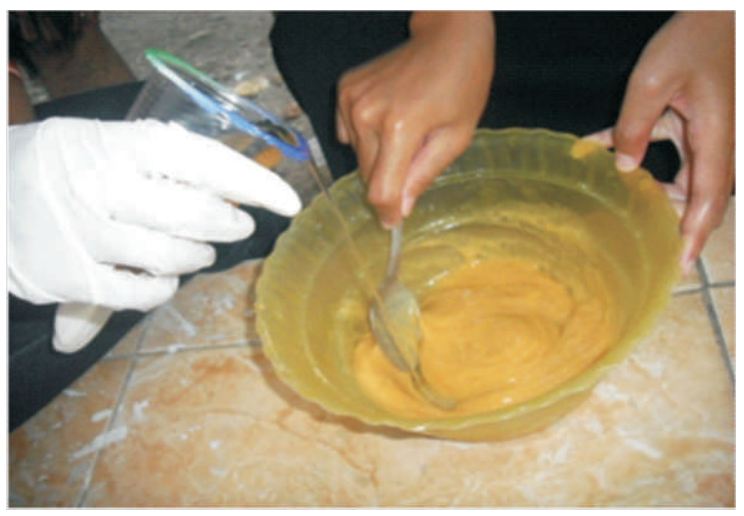

Gambar 1. Proses Pencampuran Bahan

Pada tahap pelaksanaan pembuatan sabun dari minyak jelantah bisa berjalan lancar, namun terdapat beberapa catatan permasalahan yang dihadapi selama pelaksanaan praktik, yaitu :

- Peserta kesulitan untuk menakar dalam ukuran yang pas

- komposisi campuran $\mathrm{NaOH}$ yang dirasakan belum tepat, karena sabun yang dihasilkan ketika dicoba untuk mencuci tangan terasa gatal di tangan. Solusi yang kami berikan adalah mengurangi takaran $\mathrm{NaOH}$ agar tidak menyebabkan gatal. Dengan pengurangan dosis $\mathrm{NaOH}$ menimbulkan dampak proses pemadatan sabun menjadi lebih lama

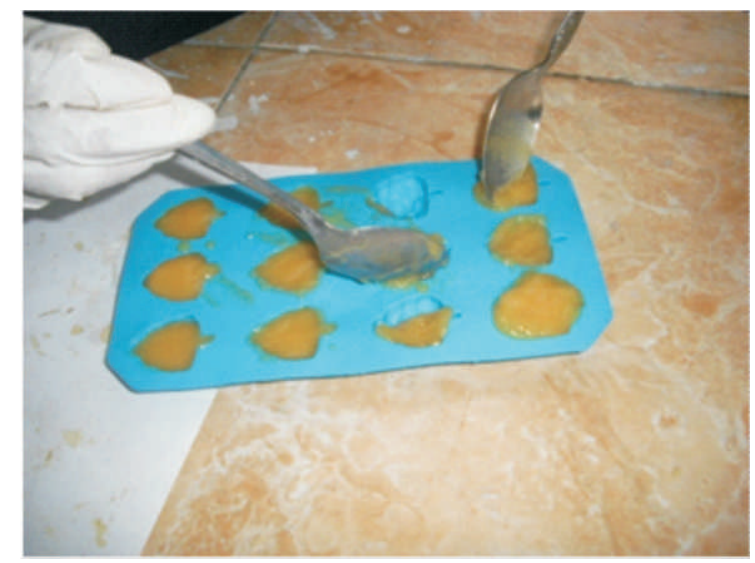

Gambar 2. Memasukkan dalam cetakan

Pada tahap evaluasi kegiatan yang kami lakukan kepada warga, kami menyimpulkan bahwa warga belum maksimal untuk melaksanakan kegiatan pemanfaatan limbah minyak jelantah untuk membuat sabun. Permasalahan yang mereka sampaikan adalah kesulitan untuk meluangkan waktu, serta enggan 
untuk mencari bahan-bahan yang diperlukan misalnya $\mathrm{NaOH}$ dan parfum. Solusi yang kami berikan adalah memberi motivasi kembali kepada warga untuk menggalakkan pemanfaatan limbah menjadi produk barang alternatif yang bermanfaat.

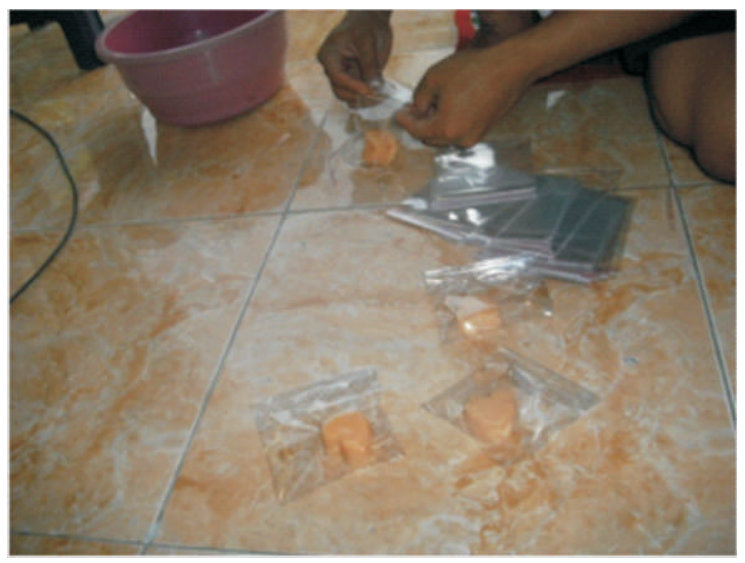

Gambar 3. Proses Pengemasan Sabun

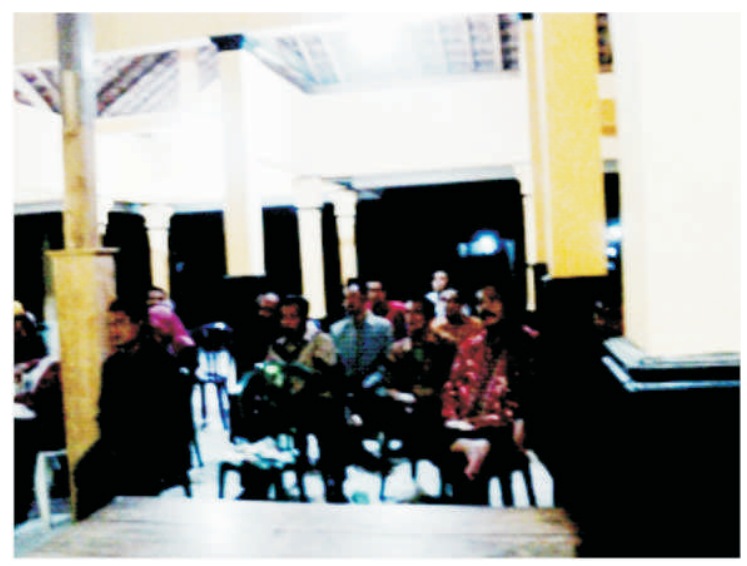

Gambar 4. Penyuluhan dan Diskusi

\section{KESIMPULAN}

Kegiatan pengabdian masyarakat melalui pelatihan pemanfaatan minyak jelantah untuk pembuatan sabun yang kami lakukan untuk warga masyarakat Desa Mojopurno secara keseluruhan dapat terserap oleh masyarakat, sehingga dapat membuka wawasan masyarakat untuk bisa kreatif dalam mengelola limbah.

Beberapa permasalahan yang dihadapi diantaranya belum terbiasanya warga untuk melakukan kegiatan sampingan untuk mengelola limbah, sehingga diperlukan motivasi dan edukasi yang lebih giat untuk membiasakan warga sadar akan kegiatan positif pemanfaatan limbah.

\section{REFERENSI}

Anonim. 2007. Panduan Nutrisi 4 Sehat 5 Sempurna. Jakarta : Departemen Kesehatan RI.

Aisiyah, Nur. 2009. Pengaruh Pemakaian Minyak Jelantah Terhadap Kadar Lemak Bebas, Iodin, dan Warna. Medan : Universitas Sumatera Utara.

Ketaren 2006. Pengantar Teknologi Minyak dan Lemak Pangan. Jakarta : Universitas Indonesia.

Widjaja, Djatmiko. 2003. Proses Pembuatan Sabun Cuci Dan Evaluasi Mutu Berdasarkan Standar Industri Indonesia. Jakarta : Balai penelitian dan pengembangan idustri.

Suhardi, Romli. 2012. Pemanfaatan Abu Sekam Padi Dalam Pembuatan Sabun Dengan Menggunakan Minyak Jelantah. Jakarta : Universitas Muhammadiyah Jakarta. 